Case report

\title{
Clustering of sebaceous gland carcinoma, papillary thyroid carcinoma and breast cancer in a woman as a new cancer susceptibility disorder: a case report
}

\author{
Brian D Newman ${ }^{1,2}$, Joseph F Maher ${ }^{3}$, Jose S Subauste ${ }^{1,4}$, \\ Gabriel I Uwaifo ${ }^{1,4}$, Steven A Bigler ${ }^{5}$ and Christian A Koch ${ }^{1,4 *}$
}

\author{
Addresses: ${ }^{1}$ Department of Medicine, Division of Endocrinology, University of Mississippi Medical Center, Jackson, MS 39216, USA \\ ${ }^{2}$ Department of Medicine, Mayo Clinic, 200 1st St SW, Rochester, MN 55905, USA \\ ${ }^{3}$ Departments of Medicine and Pediatrics, Center for Human Genetics, University of Texas Southwestern Medical Center, Dallas, TX 75390, USA \\ ${ }^{4}$ GV (Sonny) Montgomery VA Medical Center, 1500 East Woodrow Wilson Drive, Jackson, MS 39216, USA \\ ${ }^{5}$ Department of Pathology, University of Mississippi Medical Center, Jackson, MS 39216, USA
}

Email: BDN - newman.brian@mayo.edu; JFM - joseph.maher@utsouthwestern.edu; JSS - jsubauste@va.gov;

GIU - guwaifo@medicine.umsmed.edu; SAB - sbigler@pathology.umsmed.edu; CAK* - ckoch@medicine.umsmed.edu

* Corresponding author

Received: 6 February 2009 Accepted: 2 April 2009 Published: 16 July 2009

Journal of Medical Case Reports 2009, 3:6905 doi: 10.4076/1752-1947-3-6905

This article is available from: http://jmedicalcasereports.com/jmedicalcasereports/article/view/6905

(C) 2009 Newman et al.; licensee Cases Network Ltd.

This is an Open Access article distributed under the terms of the Creative Commons Attribution License (http://creativecommons.org/licenses/by/3.0),

which permits unrestricted use, distribution, and reproduction in any medium, provided the original work is properly cited.

\begin{abstract}
Introduction: Multiple distinct tumors arising in a single individual or within members of a family raise the suspicion of a genetic susceptibility disorder.

Case presentation: We present the case of a 52-year-old Caucasian woman diagnosed with sebaceous gland carcinoma of the eyelid, followed several years later with subsequent diagnoses of breast cancer and papillary carcinoma of the thyroid. Although the patient was also exposed to radiation from a pipe used in the oil field industry, the constellation of neoplasms in this patient suggests the manifestation of a known hereditary susceptibility cancer syndrome. However, testing for the most likely candidates such as Muir-Torre and Cowden syndrome proved negative.

Conclusion: We propose that our patient's clustering of neoplasms either represents a novel cancer susceptibility disorder, of which sebaceous gland carcinoma is a characteristic feature, or is a variant of the Muir-Torre syndrome.
\end{abstract}

\section{Introduction}

Multiple distinct tumors arising in a single individual or within members of a family raise the suspicion of a genetic susceptibility disorder $[1,2]$. Tumor suppressor genes, such as PTEN in Cowden syndrome and BRCA1/2 in breast cancer, function by eliciting apoptosis and G1 cycle arrest.
However, expression and tissue-specific splicing may lead to the differential expression of splice variants (SVs) with subsequent downstream signaling consequences. SVs resulting from alterations in the splicing of cancer-related genes could represent novel cases of familiar syndromes that do not reveal classic mutations. 
The diagnosis of sebaceous gland carcinoma can represent a marker of an associated heritable disorder, and some authors recommend patients be evaluated for other visceral malignancies [3]. Additionally, prompt diagnosis enables routine surveillance of occult cancers, identification of low-grade tumors that would be more responsive to treatment, and identification of family members at risk for developing cancer.

\section{Case presentation}

A 52-year-old Caucasian woman from Mississippi with a history of sebaceous carcinoma of the left lower eyelid, breast cancer of the right breast (ER+/PR+/HER2+), and papillary thyroid cancer treated by total thyroidectomy and radioactive iodine ablation $(49.5 \mathrm{mCi}$ ) was referred to our clinic for follow-up evaluation. Sebaceous gland carcinoma of the eye was diagnosed when the patient was 43-years-old and surgically treated at a hospital in Pennsylvania. She was then diagnosed with multifocal ductal carcinoma in situ of the right breast (Figure 1) in 2004 (T2NOM0), for which testing showed to be ER/PR+ as well as HER2+.

Following simple unilateral mastectomy, she initially underwent eight cycles of chemotherapy and tamoxifen treatment, but stopped taking tamoxifen secondary to fears of developing endometrial cancer in 2006. At that time, her hormone levels were checked revealing a low estradiol level $(13.9 \mathrm{pg} / \mathrm{ml})$ and an appropriately elevated follicle-stimulating hormone (FSH) $(63 \mathrm{mIU} / \mathrm{ml})$, indicative of menopause.

A mammogram from 2008 was unremarkable for recurrent cancer and she denied any vaginal bleeding. In 2005,

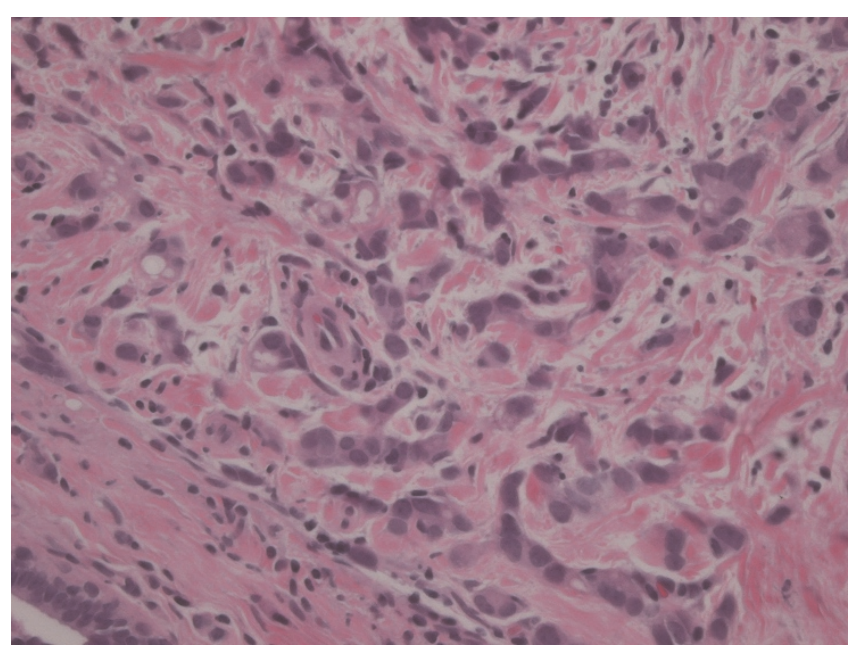

Figure I. Infiltrating ductal carcinoma of the right breast, Grade 2. H \& E stain, original magnification 400x. a papillary thyroid carcinoma (size: $0.6 \mathrm{~cm}$ ) was diagnosed after she had been found to have a thyroid nodule on routine ultrasound for which a right lobectomy was initially performed, but later followed by a total thyroidectomy in light of her multiple prior cancers.

She subsequently received ablative therapy with $49.5 \mathrm{mCi}$ of ${ }^{131}$ Iodine in 2006. Since that time, she has remained asymptomatic and is taking daily calcium tablets as well as $150 \mathrm{mcg}$ of thyroxine. Serum thyroglobulin levels had been undetectable $(<0.1 \mathrm{ng} / \mathrm{ml})$ while thyroglobulin antibodies were measured at $12 \mathrm{IU} / \mathrm{ml}$ (normal, <4.0), and thyroid stimulating hormone (TSH) at $0.006 \mathrm{mcU} / \mathrm{ml}$ ( 0.23 to $4.0 \mathrm{mcU} / \mathrm{ml})$. Sonographic examinations of her neck had been non-suspicious for recurrent cancer. Given her postmenopausal and iatrogenically-induced hyperthyroid state, she underwent a bone mineral density study that revealed osteopenia at the spine and the femur (T-score was minus 1.1). Her 25-hydroxy vitamin D level was normal at $41 \mathrm{ng} / \mathrm{ml}$.

The patient's family history was positive for breast cancer in her mother and maternal aunt. One of the patient's paternal first degree cousins suffered from an inoperable brain tumor, and a male and a female paternal second degree cousin had breast cancer. However, her family history was negative for colon cancer, endometrial or ovarian cancers, thyroid cancer, or any other cancers.

The patient recollected that her husband, who died of colon cancer, had been gainfully employed welding and cutting pipe that was previously used in the oil field industry. She further remembered being proximate to the pipe on multiple occasions, when she was helping her husband cut and weld sections, with resultant fume inhalation. After his death, she was unable to sell the pipe because it was determined to be too radioactive from its prior use in the oil field to be sold on the open market. The determination of radioactivity was made using a Geiger counter; however, the type of radiation was not determined.

Based on her personal and family history of multiple cancers, the patient underwent genetic testing for Cowden syndrome (PTEN gene testing for mutations in exons 1 to 9 was negative), screening colonoscopy (negative) to exclude Muir-Torre syndrome, hereditary nonpolyposis colorectal cancer (HNPCC) or a variant of HNPCC, and immunohistochemistry (IHC)/microsatellite instability (MSI) testing on her breast cancer specimen for HNPCC (IHC: normal pattern for hMLH1, hMSH2, hMSH6, hPMS2; MSI: BAT25, BAT26, BAT40, BAT34c mononucleotide repeats, D17s250, D5s346, D18s55, D10s197, MycL, ACTC dinucleotide). We could not rule out a PTEN promoter mutation, because this was not tested. Given 
a Manchester score of 5-7 for BRCA2 with a less than 5\% chance of finding a BRCA2 mutation, mutation analysis in BRCA1 or BRCA2 was not pursued.

\section{Discussion}

Sebaceous gland carcinoma is a rare neoplasm arising from the Meibomian glands, Zeis glands, or sebaceous glands of the caruncle and eyebrow, and represents 1-6\% of all eyelid malignancies $[4,5]$. The median age at diagnosis is 72 years, with most diagnoses prior to 30 years of age revealing a history of radiation exposure $[4,6]$. Moreover, among individuals diagnosed with sebaceous gland carcinoma, the incidence of one or more primary visceral malignancies has been noted to be as high as $42 \%$ [7].

In their report, Finan and Connolly [7], listed thyroid adenomas, uterine fibroids, and benign renal cysts as less common findings. Papillary thyroid carcinoma (PTC) is the most common thyroid malignancy worldwide, comprising $50 \%$ to $70 \%$ of differentiated follicular cell thyroid carcinomas [8-10]. PTC is strongly associated with prior irradiation to the head and neck, likely resulting in chromosome breakage and rearrangement with fusion of the RET tyrosine kinase domain to various breakpoint sites, clearly demonstrated in post-Chernobyl thyroid tumors [11,12]. Familial clustering of PTC is well recognized and family studies have revealed autosomal dominant transmission [13]. The high incidence of PTC in patients with adenomatous polyposis and Cowden syndrome (the multiple hamartoma syndrome) suggests a shared set of susceptibility genes. The genetic differential diagnosis for papillary thyroid carcinoma is shown in Table 1.

The strong family history of breast neoplasms in our patient further suggests an increased susceptibility to cancer. Breast cancer is the most common cancer in women and has been associated with a number of specific genetic mutations, namely BRCA1/2, which accounts for approximately $5 \%$ of reported cases [14]. Less frequently

Table I. Genetic Differential Diagnosis of Thyroid Cancer Associated Syndromes

\begin{tabular}{lll}
\hline Histology & Syndrome Association & Gene (if known) \\
\hline Medullary & MEN2 & RET \\
Follicular & Cowden Syndrome & PTEN \\
& Werner Syndrome & WRN \\
Papillary & Familial Adenomatous Polyposis & APC \\
& Cowden Syndrome & PTEN \\
& Carney Complex & PRKARIA \\
& Familial Nonmedullary Thyroid Cancer & \\
& Syndrome & \\
& Familial Papillary Thyroid Carcinoma & \\
\hline
\end{tabular}

Adapted from: Weber F, Eng C. Update on the Molecular Diagnosis of Endocrine Tumors: Toward-omics-Based Personalized Healthcare? J Clin Endocrinol Metab 2008, 93(4): 1097-I I04. implicated in breast cancer are PTEN in Cowden syndrome, MLH1 and MSH2 in Muir-Torre, and STK11 in Peutz-Jeghers syndrome [15-17].

Our patient presented with multiple malignant neoplasms including sebaceous gland carcinoma, papillary thyroid carcinoma, and breast cancer. Her mother who died at age 73 and maternal aunt who died at age 67 with a diagnosis of breast at around age 50, were both diagnosed with breast cancer, but both did not suffer any of the other neoplasms that were present in our patient. The clustering of visceral malignancies with sebaceous carcinoma in our patient is a unique occurrence and strongly suggests the likelihood of an underlying cancer susceptibility disorder, perhaps an under-recognized manifestation or variant of the Muir-Torre syndrome.

We considered whether these observations might be explained in the context of a known genetic cancer susceptibility disorder and felt that Muir-Torre syndrome (MTS), Cowden syndrome (CS), and Carney complex (CRC) were the most likely candidates, although none completely accounts for the pattern of neoplasms in this patient.

Muir-Torre syndrome (MTS) is an autosomal dominant disorder characterized by sebaceous gland carcinoma and one or more internal visceral malignancies (Table 2). The etiology of this disorder is thought to result from a mutation in the mismatch DNA repair genes $\mathrm{MSH}-2$ and $M L H-1$, supported by the finding of microsatellite instability in tumors of some patients $[18,19]$. However, one study shows that $31 \%$ of patients with MTS tumors exhibited no microsatellite instability, which suggests the existence of at least two variants of MTS with different molecular mechanisms [20]. MTS has also been described in the setting of MYH-related attenuated polyposis, resulting from a mutation in the MYH gene that caused aberrations in base excision repair. However, its role in the development of cutaneous sebaceous carcinogenesis is unclear [21]. Patients with MTS often have colonic polyps and adenomas, but neither is necessary to make the diagnosis. The most commonly identified neoplasms in MTS are shown in Table 3. Conventional testing on the breast cancer specimen of our patient was indicative of normal DNA mismatch repair function within the tumor. We did not perform mutation analysis of $\mathrm{MSH}-2$ and MLH-1.

Cowden syndrome (CS) is an autosomal dominant disorder distinguished by pathognomonic mucocutaneous lesions such as facial trichilemmomas, acral keratoses and papillomatosis; hamartomatous polyps, and internal visceral malignancies including breast and thyroid cancer. The causative mutation in this syndrome 
Table 2. Criteria for Diagnosis of Muirr-Torre Syndrome (MTS)

At least one:
Sebaceous Carcinoma
Sebaceous Epithelioma
Sebaceous Adenoma
Keratoacanthoma with Sebaceous differentiation
And:
I or more visceral malignancies
OR:
All of the following:
I) Family history of MTS
2) Multiple visceral malignancies
3) Multiple Keratoacanthomas

Adapted from: Weinstein et al. Muirr-Torre syndrome: a case of this uncommon entity. Int J Dermatol 2006, 45:3II-3I3.

involves the PTEN tumor suppressor gene, resulting in an unregulated progression through the G1 phase of the cell cycle.

Our patient had breast and thyroid cancer, but her lack of hamartomatous polyps and the presence of a sebaceous carcinoma cannot be readily explained in the framework of this syndrome. Furthermore, there have been no reports of sebaceous carcinoma in a patient with CS. PTC is a cancer strongly linked with radiation exposure to the head and neck and the proximity of the sebaceous carcinoma suggests that both could have resulted from a single field of exposure, in this case the radioactive piping that the patient was exposed to. Commercial testing for germline mutations in PTEN failed to show any in exons 1-9. However, a mutation is identified in only $80 \%$ of patients who meet clinical criteria $[22,23]$. On the other hand, recent data suggest that germline sequence variants in various tumor suppressor and/or oncogenes may cooperatively promote tumorigenesis of various tumor types including thyroid cancer [24-32].

Meanwhile, Carney complex is an autosomal dominant disorder that leads to endocrine gland tumors and/or hyperfunctioning commonly involving the pituitary, adrenal, and thyroid glands, as well as myxomas (skin, heart, and breast) and lentiginosis in select areas of the

Table 3. Incidence of Internal Malignancies in MTS

\begin{tabular}{ll}
\hline Site & Incidence (\%) \\
\hline Colon & $49 \%$ \\
Genitourinary & $21 \%$ \\
Breast & $11 \%$ \\
Hematologic & $9 \%$ \\
Head/Neck & $4 \%$ \\
Small Intestine & $2 \%$ \\
Other & $4 \%$ \\
\hline
\end{tabular}

Modified from: Weinstein et al. Muirr-Torre syndrome: a case of this uncommon entity. Int J Dermatol 2006, 45:3II-3I3. skin. The causative mutation involves the regulatory subunit of protein kinase receptor 1A (PRKAR1A), which results in nonsense-mediated decay of the transcript and altered protein kinase A signaling [13]. Again, the presence of breast and thyroid neoplasms is suspect, but sebaceous gland carcinoma has not been described in the setting of Carney complex. We did not test for a germline mutation of the PRKAR1A gene, which is detectable in $50-65 \%$ of cases.

The field of genomics has provided new insight on the role that splicing and other mRNA processing mechanisms serve in the regulation of gene function. Numerous examples of alterations in splicing and differential expression of SVs and their role in various sporadic cancers have been reported [33-37]. Many of the genes involved in cancer susceptibility syndromes (PTEN, APC, MSH-2) are ubiquitously expressed and tissue-specific splicing may lead to differential expression of SVs, which may suggest different roles for different SVs in different tissues. In fact, one study identified SVs of PTEN that were expressed differentially in heritable cancer, sporadic cancer, and controls. It is believed that the nonlinear, tissue-specific expression of these SVs exert varying effects at the functional or regulatory level [38].

The implication of such research becomes especially important when considering that similar gene regulation and inactivation occurs in the inherited cancer syndromes, even in the absence of identifiable gene mutations. This may in part explain the relatively low sensitivity of modern laboratory techniques that rely heavily on isolating specific mutation sequences. For instance, abnormalities in the promoter region of a gene could be missed or deletions of one or more exons on one allele.

Additionally, measurement of mRNA content in peripheral blood may aid diagnosis as well as provide novel biomarkers for the identification of certain types of cancer, possibly circumventing the need for traditionally invasive techniques such as FNA, for example, in thyroid cancer (13). Furthermore, such discoveries could pave the way for targeting anti-apoptotic SVs to lower the apoptotic threshold of a tumor cell, thereby increasing the efficacy of chemotherapy drugs. Despite the emerging evidence linking mRNA level regulation and carcinogenesis, there is limited information regarding its role in many of the well-characterized familial cancer syndromes. Very few SVs have been identified and, unfortunately, many of those that have been identified were not attributed with any functional significance [38].

\section{Conclusions}

Our patient, who had an unusual clustering of sebaceous gland carcinoma and internal malignancies, represents 
a unique clinical case. The most likely explanation would be that of either a single, unifying genetic cause resulting from a still undiscovered germline mutation, or cooperative tumorigenesis by germline sequence variants in various genes that play a role in tumor development. The history of radiation exposure was arguably the environmental catalyst for malignant transformation in this patient with an underlying genetic susceptibility. In the future, advancements in the field of genomics may allow further elucidation of the role of SVs in cancer susceptibility syndromes lacking identifiable genetic mutations.

We speculate that this patient's clustering of neoplasms represents a novel cancer susceptibility disorder, of which sebaceous gland carcinoma is a characteristic feature. This hypothesis cannot be tested on the basis of a single case report; therefore, we await further contributions from other clinical investigators.

\section{Consent}

Written informed consent was obtained from the patient for publication of this case report and any accompanying images. A copy of the written consent is available for review by the Editor-in-Chief of this journal.

\section{Competing interests}

The authors declare that they have no competing interests.

\section{Authors' contributions}

$\mathrm{BN}$ and $\mathrm{CK}$ drafted the manuscript. JM initiated genetic testing. JM, JS, and GU provided valuable medical input. SB made photographs of important histological slides. All authors read and approved the final manuscript.

\section{References}

I. Georgitsi M, Heliovaara E, Paschke R et al: Large genomic deletions in AIP in pituitary adenoma predisposition. J Clin Endocrinol Metab 2008, 93:4I46-4I5I.

2. Koch CA: Molecular pathogenesis of MEN2-associated tumors. Fam Cancer 2005, 4:3-7.

3. Demirci H, Nelson CC, Shields CL, Eagle RC Jr, Shields JA: Eyelid sebaceous carcinoma associated with Muir-Torre syndrome in two cases. Ophthal Plast Reconstr Surg 2007, 23:77-79.

4. Shields JA, Demirci H, Marr BP, Eagle RC Jr, Shields CL: Sebaceous Carcinoma of the Eyelids: Personal Experience with 60 Cases. Ophthalmology 2004, I I I:2I5I-2I 57.

5. Kass LG, Hornblass A: Sebaceous carcinoma of the ocular adnexa. Surv Ophthalmol 1989, 33:477-490.

6. Chao AN, Shields $\mathrm{Cl}$, Krema H, Shields JA: Outcome with periocular sebaceous gland carcinoma with and without conjunctival intraepithelial invasion. Ophthalmology 200I, 108:1877-I883.

7. Finan MC, Connolly SM: Sebaceous gland tumors and systemic disease: a clinicopathologic analysis. Medicine 1984, 63:63-70.

8. Hay ID: Papillary thyroid carcinoma. Endocrinol Metab Clin North Am 1990, 19:545-576.

9. Hay ID, Hutchinson ME, Gonzales-Losada T, Mclver B, Reinalda ME, Grant CS, Thompson GB, Sebo T], Goellner JR: Papillary thyroid microcarcinoma: a study of 900 cases observed in a 60 -year period. Surgery 2008, 144:980-987.
10. Hay ID, Thompson GB, Grant CS, Bergstralh EJ, Dvorak CE, Gorman GA, Maurer MS, Mclver B, Mullan BP, Oberg AL, Powell CC, van Heerden JA, Goellner JR: Papillary thyroid carcinoma managed at the Mayo Clinic during six decades (1940-1999): temporal trends in initial therapy and long-term outcome in $\mathbf{2 4 4 4}$ consecutively treated patients. World J Surg 2002, 26:879-885.

II. Nikiforov YE: Thyroid carcinoma: molecular pathways and therapeutic targets. Mod Pathol 2008, 21:S37-S43.

12. Koch CA, Sarlis NJ: The spectrum of thyroid diseases in childhood and its evolution during transition to adulthood: natural history, diagnosis, differential diagnosis and management. J Endocrinol Invest 200I, 24:659-675.

13. Weber F, Eng C: Update on the Molecular Diagnosis of Endocrine Tumors: Toward -omics-Based Personalized Healthcare? J Clin Endocrinol Metab 2008, 93:1097-I 104.

14. Rippberger T, Gadzicki D, Meindl A, Schlegelberger B: Breast cancer susceptibility: current knowledge and implications for genetic counseling. Eur J Hum Genet 2008, 17:722-73I.

15. Celebi JT, Wanner M, Ping XI et al: Association of splicing defects in PTEN leading to exon skipping or partial intron RETention in Cowden syndrome. Hum Genet 2000, 107:234-238.

16. Propeck PA, Warner T, Scanlan KA: Sebaceous carcinoma of the breast in a patient with Muir-Torre syndrome. AJR 2000, I74:54I-542.

17. Chen J, Lindblom A: Germline mutation screening of the STK I I/LKB I gene in familial breast cancer with LOH on I9p. Clin Genet 2000, 57:394-397.

18. Entius MM, Keller JJ, Drillenburg $P$ et al: Microsatellite instability and expression of hMLH-I and hMSH-2 in sebaceous gland carcinomas as markers for Muir-Torre Syndrome. Colon Cancer Res 2000, 6: 1784-1789.

19. Honchel R, Halling KC, Schaid DJ: Microsatellite instability in Muir-Torre syndrome. Cancer Res 1994, 54: I I59-I I63.

20. Weinstein A, Nouri K, Bassiri-Tehrani S, Jimenez G: Muir-Torre syndrome: a case of this uncommon entity. Int J Dermatol 2006, 45:3II-3I3.

21. Ponti G, Ponz de Leon M, Pedroni M et al: Attenuated familial adenomatous polyposis and Muir-Torre syndrome linked to compound biallelic constitutional MYH gene mutations. Clin Genet 2005, 68:442-447.

22. Phoung M, Korde L, Kramer J et al: A possible new syndrome with growth-hormone secRETing pituitary adenoma, colonic polyposis, lipomatosis, lentigines and renal carcinoma in association with familiar testicular germ cell malignancy: A case report. J Med Case Rep 2007, 1:9.

23. Chibon F, Primois C, Bressieux JM, Lacombe D, Lok C, Mauriac L, Taieb A, Longy M: Contribution of PTEN large rearrangements in Cowden disease: a MAPH screening approach. J Med Genet 2008, 45:657-65

24. Zbuk KM, Patocs A, Shealy A, Sylvester H, Miesfeldt S, Eng C: Germline mutations in PTEN and SDHC in a woman with epithelial thyroid cancer and carotid paraganglioma. Nat Clin Pract Oncol 2007, 4:608-612.

25. Ni, Zbuk KM, Sadler T, Patocs A, Lobo G, Edelman E, Platzer P, Orloff MS, Waite KA, Eng C: Germline mutations and variants in the succinate dehydrogenase genes in Cowden and Cowdenlike syndromes. Am J Hum Genet 2008, 83:26I-268.

26. Plon SE, Pirics ML, Nuchtern J, Hicks J, Russel H, Agrawal S, Zbuk K, Eng $C$, Hegde M, Chin EPH: Multiple tumors in a child with germline mutations in TP53 and PTEN. N Engl J Med 2008, 359:537-539.

27. Frew IJ, Minola A, Georgiev S, Hitz M, Moch H, Richard S, Vortmeyer AO, Krek W: Combined VHLH and PTEN mutation causes genital tract cystadenoma and squamous metaplasia. Mol Cell Biol 2008, 28:4536-4548.

28. Donnellan KA, Bigler SA, Wein RO: Papillary thyroid carcinoma and familial adenommatous polyposis of the colon. Am J Otolaryngol 2009, 30:58-60.

29. Ahmad S, Aaltonen LA, Georgitsi M, Parent A, Fratkin J, GomezSanchez EP, Koch CA: Do single nucleotide polymorphisms in the AIP gene and MEN I gene predispose individuals to the development of familial isolated pituitary tumors? Exp Clin Endocrinol Diabetes 2007, I I 5:S35-S36. 
30. Koch CA, Friedrich CA, Majumdar S, Fraktin JD, Moll GW: Novel splice donor region DNA sequence variant in the succinate dehydrogenase subunit B gene in a boy with malignant paraganglioma in a family with non-classical congenital adrenal hyperplasia. Exp Clin Endocrinol Diabetes 2007, I I5:S39.

31. Koch CA, Brouwers FM, Vortmeyer AO, Tannapfel A, Libutti SK, Zhuang Z, Pacak K, Neumann HPH, Paschke R: Somatic VHL gene alterations in MEN 2-associated medullary thyroid carcinoma. BMC Cancer 2006, 6: I3I.

32. Koch CA, Huang SC, Zhuang Z, Stolle C, Azumi N, Chrousos GP, Vortmeyer AO, Pacak K: Somatic VHL gene deletion and point mutation in MEN 2A-related pheochromocytoma. Oncogene 2002, $21: 479-482$.

33. Orban $\mathrm{TI}$, Olah E: Expression profiles of BRCAI splice variants in asynchronous and in GI/S synchronized tumor cell lines. Biochem Biophys Res Commun 200I, 280:32-38.

34. Sato N, Hori O, Yamaguchi I, Lambert JC et al: A novel presenilin-2 splice varian in human Alzheimer's disease brain tissue. J Neurochem 1999, 72:2498-2505.

35. Vijayakrishnan L, Slavik JM, Illes $Z$ et al: An autoimmune diseaseassociated CTLA-4 splice variant lacking the B7 binding domain signals negatively in T cells. Immunity 2004, 20:563-575.

36. Weng MW, Lai JC, Hsu CP et al: Alternative splicing of MDM2 mRNA in lung carcinomas and lung cell lines. Environ Mol Mutagen 2005, 46:I-II.

37. Rohaly G, Chemnitz J, Dehde $S$ et al: A novel human p53 isoform is an essential element of the ATR-intra-S phase checkpoint. Cell 2005, I 22:21-32.

38. Agrawal S, Eng C: Differential expression of novel naturally occurring splice variants of PTEN and their functional consequences in Cowden syndrome and sporadic breast cancer. Hum Mol Genet 2006, I5:777-787.

\section{Do you have a case to share?}

Submit your case report today

- Rapid peer review

- Fast publication

- PubMed indexing

- Inclusion in Cases Database

\section{Any patient, any case, can teach us something}

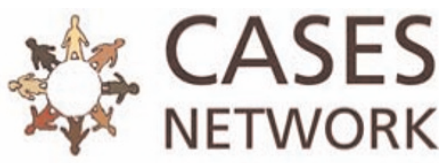

www.casesnetwork.com 